\title{
Pemetaan Fungsi Platforn E-Portofolio Untuk Perkuliahan di Jurusan Kurikulum dan Teknologi Pendikan Fakultas llmu Pendidikan Universitas Negeri Jakarta
}

\author{
Nurdin Ibrahim ${ }^{1}$ \\ R.A. Hirmana Wargahadibrata ${ }^{2}$
}

\begin{abstract}
The purpose of this study is the to Mapping the three characteristic of the eportfolios platform. This research was conducted by the design and development research method by using two methodologies: (1)Tool Use, (2) Model Development. This study collecting various types of platforms specialized to the development eportfolios and will do a mapping of the function of the platform that has been ellected. To achieve the goal the first year will be used Expert Reviews surveys method The experts will give ratings to the three pieces of E-portfolio Platform installedin www.eportofolio.ac.id, namely Elgg, Moodle and Mahara. Based on these results, the researchers conclude Mahara Platform is the appropriate platform to be used in the learning process. It is supported ratings obtained from the experts.
\end{abstract}

Keywords: e-Portofolio, Elgg, Moodle, Mahara, Platform

\begin{abstract}
Abstrak: Tujuan penelitian ini adalah untuk memetakan tiga karakteristik paltform eportofolio. Penelitian ini dilakukan dengan jenis penelitian Design and Development research (DDR) menggunakan dua metodologi: (1) Tool Use dan (2) model Penelitian devepment. Penelitian ini mengumpulkan berbagai tipe palfform e-portofolio yang secara khusus ditujukan pada pengembangan $e$-portofolio dan dilakukan pemetaan fungsi platform terpilih. Platform e-portofolio yang dipetakan pertama sebanyak enam model. Setelah dilakukan pengkajian oleh team, maka terpilih tiga platform. Ketiga platform tersebut, kemudian divalidasi oleh dua orang pakar dari luar dan dua pakar dari dalam Fakultas Ilmu Pendidikan. Para pakar akan memberikan penilaian terhadap tiga platform e-portofolio yang telah diinstal pada www.eportofolio.ac.id meliputi: Elgg, Moodle dan Mahar. Berdasarkan penilaian pakar, peneliti menyimpulkan bahwa platform mahara merupakan yang tepat digunakan dalam proses belajar.
\end{abstract}

Kata Kunci: e-portofolio, Platform, Elgg, Moodle Mahara,

\section{PENDAHULUAN}

Karakteristik pembelajaran di Perguruan

Tinggi menurut Peraturan Menteri Tahun 2014 nomor 049 mengenai Standar Nasional Pendidikan Tinggi terdiri atas sifat interaktif, holistik, integratif, saintifik, kontekstual, tematik, efektif, kolaboratif, dan berpusat pada mahasiswa. Untuk mendukung proses pembelajaran tersebut maka penilaian yang dilakukan di Perguruan Tinggi memiliki beberapa prinsip penilaian, yaitu mencakup prinsip edukatif, otentik, objektif, akuntabel, dan transparan yang dilakukan secara terintegrasi. Adapun Peraturan Menteri tersebut penilaian dapat dilakukan dengan menggunakan beberapa instrumen penilaian, yaitu penilaian proses dalam bentuk rubrik dan/atau penilaian hasil dalam bentuk portofolio atau karya desain.

Portofolio merupakan koleksi dari pekerjaan-pekerjaan peserta didik sebagai bukti kemajuan pembelajar atau kelompok pembelajar,

\footnotetext{
${ }^{1}$ Nurdin Ibrahim, Guru Besar Tetap Universitas Negeri Jakarta, email nurdin 1349@yahoo.co.id

${ }^{2}$ R.A. Hirmana Wargahadibrata, Dosen Kurikulum dan Teknologi Pendidikankan, Universitas Negeri Jakarta
} 
bukti prestasi, keterampilan, dan sikap pembelajar. Portofolio menampilkan pekerjaan peserta didik yang terbaik atau karya peserta didik yang paling berarti sebagai hasil kegiatannya sehingga mengilustrasikan kemajuan belajar peserta didik. Portofolio merupakan satu cara agar dalam diri peserta didik tumbuh kepercayaan diri bahwa dia mampu mengerjakan tugas. Dengan tumbuhnya kepercayaan diri pada diri peserta didik diharapkan dapat memotivasinya untuk mencari pengetahuan dan pemahaman sendiri serta berkreasi dan terbuka ide-ide baru yang mereka lakukan dalam kegiatan pembelajarnya.

Agar implementasi penggunaan portofolio dapat berjalan dengan baik, maka perlu diperhatikan prinsip-prinsip dalam mendokumentasikan portofolio sebagaimana dijelaskan oleh Suryapranata dan Hatta mengenai prinsip-prinsip dokumentasi portofolio dalam bukunya yang berjudul Penilaian Portofolio, Implementasi Kurikulum 2004, yaitu sebagai berikut: (1) Akurasi data, (2) Ketepatan waktu, (3) Kelengkapan informasi, (4) Keterbacaan dokumen, (5) Kepraktisan dokumen, (6) Perencanaan, (7) Penataan dokumen, (8) Pengadministrasian dokumen. (Suryapranata dan Hatta, 2006:42-46).

Berdasarkan prinsip portofolio tersebut, portofolio konvensional (mengguna-kan kertas) mengalami beberapa hambatan dalam pelaksanaannya. Tingkat akurasi data portofolio konvensional tidak dapat diperbaharui sesuai perkembangan informasi, karena jika sudah dalam format kertas, data menjadi lebih statis. Adapun untuk butir prinsip kepraktisan dokumen pada portofolio konvensional juga akan mengalami kendala, karena tuntutan portofolio akan menghasilkan tumpukan kertas dalam jumlah banyak, hal ini tentu tidak praktis.

Oleh karena itu, sesuai dengan perkembangan teknologi maka format portofolio saat ini berkembang menjadi elektronik portofolio (e-portofolio). Potensi dari e-portofolio sama besar dengan potensi portofolio konvensional hanya melalui $e$-portofolio sifat dinamis teknologi akan menyertai format ini. Saat ini sudah banyak software yang dapat digunakan untuk mengembangkan $e$ portofolio, baik software yang berdiri sendiri (stand alone) ataupun software yang dirangkaikan dalam sebuah Learning Content Management System (LCMS).

Jurusan Kurikulum dan Teknologi Pendidikan Universitas Negeri Jakarta merupakan Jurusan yang telah memiliki Learning Content Management System (LCMS) berbasis Platform Claroline pada tahun 2009, dan hingga kini terus melakukan pengembangan dalam ranah pembelajaran hibrida (memadukan model pembelajaran dengan tujuan perbaikan proses dan hasil belajar). Dengan melihat potensi $e$-portofolio dan kesesuaian pola pembelajaran Platform Claroline yang selama ini dimiliki, serta kesesuaian dengan tuntutan kurikulum yang ada maka pada tahun 2015 ini direncanakan sebuah perkembangan pembelajaran hibrida dengan penerapan $e$-portofolio untuk perkuliahan di Jurusan Kurikulum dan Teknologi Pendidikan Universitas Negeri Jakarta.

Penelitian ini adalah penelitian longitudinal yang dilakukan selama dua tahun dengan tujuan umum penelitian ini adalah mendapatkan pemetaan fungsi platform e-portofolio untuk perkuliahan di Jurusan Kurikulum dan Teknologi Pendidikan Universitas Negeri Jakarta. Adapun tujuan khusus 
penelitian ini adalah memetakan karakteristik tiga buah platform e-portofolio.

Istilah asesmen (assessment) diartikan oleh Stiggins (1994) sebagai penilaian proses, kemajuan, dan hasil belajar siswa (outcomes). Sementara itu asesmen diartikan oleh Kumano (2001) sebagai “ The process of Collecting data which shows the development of learning". Dengan demikian dapat disimpulkan bahwa asesmen merupakan istilah yang tepat untuk penilaian proses belajar peserta didik.

Meskipun proses belajar peserta didik merupakan hal penting yang dinilai dalam asesmen, faktor hasil belajar juga tetap tidak dikesampingkan. Gabel (1993: 388-390) mengkategorikan asesmen ke

Tabel 1. Perbedaan Asesmen Tradisional dengan Asesmen Alternatif

\begin{tabular}{|c|c|}
\hline $\begin{array}{c}\text { Asesmen tradisional } \\
\text { (Tes) }\end{array}$ & As \\
\hline $\begin{array}{l}\text { 1. Penilaian } \\
\text { dilakukan untuk } \\
\text { menilai } \\
\text { kemampuan } \\
\text { peserta didik } \\
\text { berikan jawaban } \\
\text { benar } \\
\text { 2. Tes diberikan } \\
\text { tidak } \\
\text { berhubungan } \\
\text { dengan realitas } \\
\text { kehidupan peserta } \\
\text { didik } \\
\text { 3. Tes terpisah dari } \\
\text { pembelajaran } \\
\text { yang dilakukan } \\
\text { 4. Dapat diskor } \\
\text { dengan } \\
\text { reliabilitas tinggi } \\
\text { 5. Hasil tes } \\
\text { diberikan dalam } \\
\text { bentuk skor }\end{array}$ & $\begin{array}{l}\text { 1. } \begin{array}{l}\text { Penilaian } \\
\text { dilakukan untuk } \\
\text { menilai kualitas } \\
\text { produk atau unjuk } \\
\text { kerja peserta didik. }\end{array} \\
\text { 2. } \begin{array}{l}\text { Tugas diberikan } \\
\text { berhubungan } \\
\text { dengan realitas }\end{array} \\
\text { kehidupan peserta } \\
\text { didik. } \\
\text { Terdapat integrasi } \\
\text { pengetahuan } \\
\text { dengan kinerja atau } \\
\text { produk mendapatkan } \\
\text { 4. } \begin{array}{l}\text { Sulit ment dengan } \\
\text { skor asesmen } \\
\text { reliabilitas tinggi }\end{array} \\
\text { 5asil asengan } \\
\text { diberikan dengan } \\
\text { bentuk kinerja }\end{array}$ \\
\hline
\end{tabular}

Dengan pemaparan tabel di atas, dirasakan selain pola asesmen tradisional maka diperguruan tinggi dibutuhkan pula jenis pola penilaian alternatif dalam proses pembelajaran.

Kata portofolio berasal dari bahasa Italia dalam kedua kelompok besar yaitu asesmen tradisional dan asesmen alternatif. Asesmen yang tergolong konvensional adalah tes benar-salah, tes pilihan ganda, tes melengkapi, dan tes jawaban terbatas. Sementara itu yang tergolong ke dalam asesmen alternatif (non-tes) adalah essay/uraian, penilaian praktek, penilaian proyek, kuesioner, inventori, daftar Cek, penilaian oleh teman sebaya/sejawat, penilaian diri (self assessment), portofolio, observasi, diskusi dan interviu (wawancara). Berikut pemaparan mengenai perbedaan asesmen tradisional dengan asesmen alternatif yang dikemukakan oleh Zulkifli Matondang.

"portare fogliou" yang berarti "membawa kertas" dan telah digunakan secara luas dalam berbagai profesi, seperti kesenian, fotografi, arsitektur dan musik selama beberapa dekade (Rassin et al. dalam Fiona Timmins, 2008: 22). Meskipun dalam konteks pendidikan, portofolio baru populer pada awal 1990an, portofolio memiliki keterkaitan yang sangat erat dengan proses belajar dan pembelajaran.

Portofolio merupakan kumpulan atau arsip pribadi dari peserta didik yang dapat menunjukkan proses perkembangan siswa dengan melakukan pemeriksanaan terhadap hasil yang telah dikumpulkan secara rinci. Hal ini sebagaimana definisi yang dikemukakan Arter dan Spandel (1991) portofolio sebagai refleksi studi seorang peserta didik dengan tujuan menyajikan keberhasilan mereka dalam satu bidang atau lebih. Menurut definisi wikipedia, portofolio adalah koleksi pribadi seorang peserta didik yang mendokumentasikan keberhasilan atau pencapaiannya dalam pembelajaran.

Kumpulan arsip dalam wujud kertas pada 
awalnya digunakan dalam sebuah proses penelitian, namun dengan perkembangan teknologi, para peneliti mulai menjaga studi mereka dengan memanfaatkan elektronik seperti kaset, disket, CD, DVD dan removable disk. Jenis portofolio ini lebih efektif, karena dapat menyimpan materi audio dan video, potofolio jenis ini disebut sebagai portofolio elektronik (e-portofolio). Menurut ahli portofolio David Niguidula (2011), e-portofolio adalah perangkat lunak yang membantu siswa untuk menyajikan penguasaan dan keterampilan mereka dalam cara yang lebih kaya (dalam hal ini menggunakan bantuan teknologi).

Menurut Chang dan Tung dalam Wenyin (2004:227), penggunaan utama portofolio dalam pembelajaran adalah untuk merekam kinerja dan kemajuan peserta didik selama proses pembelajaran. guru juga dapat menggunakan portofolio untuk membangun profil peserta agar mendapatkan pemahaman tentang siswa selama proses pembelajaran berlangsung. Pembelajaran berbasis portofolio tidak semata-mata untuk kepentingan guru dalam mengevaluasi siswa, tetapi juga memberikan siswa kesempatan untuk mengembangkan diri dan sebagai alat evaluasi diri. Dengan demikian, selain sebagai alat evaluasi, portofolio juga dapat berfungsi untuk motivasi bagi siswa agar mengubah sikap pasif dalam menerima materi perkuliahan menjadi lebih aktif mengumpulkan dan mengorganisir bahan belajar mereka karena mereka memperoleh rasa kepemilikan atas portofolio mereka sendiri.

Esensi dari pembelajaran berbasis portofolio adalah koleksi yang membuktikan telah terjadinya belajar. Pembelajaran berbasis (Brown, Bull and Pedlebury, 1997:187). Portofolio merupakan pengalaman belajar siswa yang yang memberikan bukti refleksi dan pembelajaran. Sebuah kegiatan pembelajaran tidak dengan sendirinya bukti belajar sebagaimana asumsi banyak orang yang menganggap belajar. Menghadiri kegiatan pembelajaran belum dapat membuktikan telah terjadi belajar, sehingga pada saat siswa terlibat dapat kegiatan pembelajaran, sangat pentingan bagi guru untuk memberikan kesempatan kepada mereka untuk merefleksikan pengalaman belajar dan memperkuat pengetahuan, sikap, dan keterampilan dengan mencatat semua kegiatan belajar dan hasil yang telah mereka peroleh dalam sebuah portofolio. Portofolio juga memberikan kesempatan bagi siswa menemukan kebutuhan belajar mereka sehingga memungkinkan mereka untuk merencanakan bagaimana memenuhi kebutuhan tersebut. Proses pembelajaran seperti ini disebut dengan pembelajaran berbasis portofolio, yang mencakup proses dan produk. Proses menyimpan (menyimpan catatan, membuat catatan, dan menulis catatan harian) melibatkan siswa dalam refleksi atas pengalaman atau belajar aktivitas mereka yang akan memberikan mereka mekanisme untuk melakukan reffleksi dan memperkuat belajar. Selain itu, portofolio akan menghasilkan sebuah produk yang akan menyediakan siswa sebuah log dari pengalaman belajar mereka yang dapat menjadi bagian dari kurikulum vitae mengesankan.

Portofolio konvensional dan $e$-portofolio, kedua jenis portofolio ini memiliki kesamaan tujuan, hanya dengan e- portofolio kesempatan dan dukungan teknologi dapat memberikan nilai lebih proses pembelajaran. Dengan memanfaatkan pendekatan e-portofolio memungkinkan untuk : 
1) Peserta didik dapat mengembangkan sikap positif terhadap proses pembelajaran karena mempunyai rasa kepemilikan, dapat melakukan kontrol selama dalam proses pembelajaran, serta mengetahui arah/tujuan pembelajaran.

2) Peserta didik memiliki jalur pembelajaran individual namun masih dapat melakukan pembelajaran kolaboratif.

3) Meningkatkan pembelajaran pedagogi.

4) Mendokumentasikan pengembangan kompetensi utama peserta didik.

5) Peserta didik dapat merefleksikan kemajuan dan prestasi mereka selama proses pembelajaran.

6) Pembelajaran online menyediakan kesempatan yang sama bagi semua anggota kelompok untuk berkontribusi.

7) Penggunaan alat multi-media (kamera, scanner, kamera video, kamera mini (usb), video, perekam audio, podcast, ipod, ipad, internet itu sendiri) memberikan kesempatan dapat menangkap emosi siswa selama melaksanakan pembelajaran.

8) Adanya dukungan (umpan balik dan umpanmaju) selama proses pembelajaran berlangsung.

9) Jejaring sosial akan membantu peserta didik belajar terlibat secara efektif dan bertanggung jawab.

10) Adanya kesempatan belajar kolaboratif.

11) Memungkinkan menciptakan jaringan koneksi yang lebih luas.

E-portofolio didasarkan pada pandangan konstruktivisme dalam hal mempromosikan inisiatif dan mendorong refleksi diri. Melalui pembelajaran berbasis $e$-portofolio memiliki otonomi dalam memilih produk yang akan digunakan untuk mengevaluasi pembelajaran mereka. Mereka diharapkan untuk membedah dan menilai produk berdasarkan upaya pembelajaran mereka sebelumnya. Mereka juga diminta untuk membuat (dan menjelaskan) pilihan-pilihan rasional yang akan digunakan dalam portofolio akhir untuk didemonstrasikan pada publik. Akibatnya, refleksi diri siswa mengharuskan mereka untuk terlibat dalam dialog pribadi yang memberikan kontribusi lebih dalam dan lebih bermakna dari model-model pembelajaran pada umumnya yang melakukan penilaian dengan kertas dan pensil (Venezky \& Oney dalam Nicole Buzzetto-Moore, 2010: 120).

Dalam pandangan konstruktivisime, pembelajaran berbasis e-portofolio merupakan lingkungan belajar di mana peserta didik membangun makna. Ini mengasumsikan bahwa makna dan tujuan belajar siswa bervariasi pada setiap individu dari waktu ke waktu, dan portofolio menyajikan proses, catatan proses yang terkait dengan belajar itu sendiri sesuai dengan karakteristik setiap siswa (Martina Kelly dalam Nona Lyon: 2010:369). Menurut Buzzetto-More (2010), dengan kumpulan karya yang tersimpan dalam e-portofolio, siswa siswa yang menunjukkan kemajuan dan prestasi dalam subjek atau konten area tertentu meliputi: (1) partisipasi siswa dalam pemilihan karya yang akan dikirimkan; (2) kontribusi siswa dalam pembentukan kriteria penilaian; dan (3) bukti sistematis dari refleksi diri siswa

Konsep pembelajaran berbasis e-portofolio juga sangat terhubung dengan ide praktek reflektif. Istilah "praktek reflektif. Helen Barrett, dalam Lorraine Stefani, Robin Mason, and Chris Pegler (2007:74) mengemukakan bahwa e-portofolio yang 
bertujuan untuk mendorong pertumbuhan belajar didasarkan pada belajar' model konstruktivisme. Dia menunjukkan bahwa pengembangan e-portofolio mencerminkan prinsip konstruktivisme dalam yang memungkinkan siswa untuk memulai belajar mereka dari titik awal yang berbeda. umpan balik formatif atau kritik yang mengembangkan wawasan siswa serta mendorong refleksi dan revisi. Dalam hal ini, portofolio adalah alat untuk mendukung proses pembelajaran dan penilaian formatif. portofolio menjadi 'cerita' pembelajaran yang dimiliki oleh setiap siswa.

E-Portofolio untuk penilaian adalah koleksi pekerjaan yang menunjukkan prestasi di lapangan, program, atau proyek . E-portofolio untuk penilaian dapat secara mengukur softskill, seperti keterampilan berpikir kritis dan pemecahan masalah. Seperti halnya E-portofolio untuk belajar, komponen-komponen E-portfolio untuk penilaian sebagain besar memuat proses refleksi dan penilaian diri

Portofolio untuk penilaian umumnya digunakan dalam situasi di mana siswa tidak diuji atau dinilai dengan cara konvensional, melainkan dengan memberikan bukti kompetensi mereka di bidang studi tertentu. Siswa dapat memberikan fotofoto, rekaman temuan melalui video, laporan reflektif. Jenis portofolio ini memliki keuntungan tertentu yang dalam penilaian pembelajaran berbasis kerja serta sangat berguna dalam situasi di mana penilaian mungkin tidak menjadi sesuatu yang bisa dilakukan dalam kondisi normal

contohnya adalah untuk instalasi seni. Pada kasus ini memungkinkan fleksibilitas dan kreativitas siswa dalam memberikan bukti dari pekerjaan dan hasil karya mereka.
Portofolio untuk penilaian merupakan aspek utama dari strategi pembelajaran dan penilaian. eportofolio sangat cocok dengan ide pembelajaran dan penilaian otentik dimana siswa harus dinilai pada kinerja mereka karena hal ini berkaitan dengan potensi mereka. Menggunakan kontrak pembelajaran yang telah dinegosiasikan sebelumnya, pekerjaan ini bisa disajikan dalam e-portofolio dengan siswa memilih sendiri pekerjaan yang akan mereka presentasikan berdasarkan evaluasi diri.

Sufeng Yan, Runjuan Song, and Liming Sun dalam Jia Luo (2012: 757-758) mengidentifkasi 3 (tiga) keuntungan dari pemanfaatan portofolio untuk pembelajaran, yaitu sebagai berikut:

Pertama, isi utama dari portofolio adalah karya siswa. Hal ini berbeda dari cara tradisional penilaian. Ini adalah karakteristik. Terutama mengumpulkan berbagai jenis karya dari pembelajaran sehari-hari siswa. Bahan-bahan yang dikumpulkan menunjukkan prestasi siswa dan kemajuan belajar mereka. Hal ini juga mendokumentasikan proses dan strategi belajar siswa. status dan sikap emosional siswa ditunjukkan juga.

Kedua, koleksi karya siswa dikembangkan dengan disengaja. Jika tujuan membangun portofolio adalah untuk menunjukkan prestasi siswa, dokumendokumen yang terbaik dan paling penting harus dimasukkan. Namun jika dimaksudkan untuk merekam perkembangan belajar siswa, materi-materi yang terkait dengan aktivitas belajar yang harus dimasukkan. Ini akan mempermudah guru untuk menemukan peningkatan belajar siswa untuk membandingkan portofolio yang berbeda sehingga akan lebih jelas terlihat peningkatan siswa dari berbagai aspek.

Ketiga, Penilaian tradisional menempatkan terlalu 
banyak tekanan pada klasifikasi dan seleksi serta hasil belajar. Hal ini menyebabkan penekanan yang berlebihan pada nilai ujian. portofolio mengumpulkan data yang dihasilkan selama proses pembelajaran, terutama tentang proses pembelajaran, strategi pembelajaran, kelemahan dan kekuatan perkembangan siswa, sehingga guru dapat memberikan saran untuk membantu siswa setelah menganalisis data-data yang telah mereka dikumpulkan.

Beberapa hasil penelitian menunjukkan efektivitas pemanfaatan $e$-portofolio, baik untuk tujuan pembelajaran (McNeill dan Cram, 2011), penilaian (Buzzetto-More, 2010), refleksi dan regulasi diri (Yastibas dan Yastibas, 2014, Wang, 2009), maupun pengembangan karir mahasiswa (Tubaishat, 2015).

Evaluasi yang dilakukan McNeil dan Cram (2011) terhadap pemanfaatan $e$-portofolio untuk pembelajaran menunjukkan bahwa $e$-portofolio berbasis web dapat menyediakan ruang bagi mahasiswa untuk mengembangkan keahlian dengan ruang lingkup pengetahuan dan keterampilan yang lebih luas. Penelitian bertujuan untuk mengetahui persepsi mahasiwa terhadap implementasi platform mahara di sebuah perguruan tinggi di Australia ini menemukan bahwa e-portofolofio sangat efektif mendukung efektvitas pembelajaran. Mengacu pada hasil penelitian ini McNeill dan Cram (2011) merekomendasikan pemanfaatan $e$-portofolio perlu diintegrasikan ke dalam proses belajar dan pembelajaran, serta mahasiswa perlu mendapatkan pemahaman tentang pemanfaatannya agar dapat mengoptimalkan keuntungan-keuntungan dari fiturfitur yang tersedia dalam aplikasi $e$-portofolio.

Terkait dengan pemanfaatan $e$-portofolio untuk penilaian, Buzzetto-More

(2010) menyimpulkan bahwa $e$-portofolio merupakan suatu paradigma dalam pembelajaran konstruktivisme. Aplikasi ini memiliki kemampuan untuk melibatkan siswa untuk belajar lebih mendalam serta menyediakan penilaian berbasis outcome baik bagi mahasiswa, dosen, maupun fakultas. Menurut hasil penelitiannya, e-portofolio menunjukkan cara yang valid dalam mendokumentasikan proses belajar mahasiswa, mendorong keterlibatan mahasiswa yang lebih besar ke dalam proses pembelajaran, menyediakan ruang bagi mahasiswa untuk memamerkan hasil belajar mereka, serta menyediakan metode evaluasi untuk penilaian hasil belajar dan kurikulum.

Yastibas dan Yastibas (2015) dalam penelitian mereka menemukan bahwa e-portofolio dapat digunakan secara efektif sebagai penilaian dalam pembelajaran, dapat meningkatkan gaya belajar yang berbeda dari peserta didik serta mendukung kemandirian belajar. Kompetensi $e$ portofolio tidak hanya tergantung pada kelimpahan artefak, tetapi juga efektivitas penggunaan $e$ portofolio untuk belajar aktif. Hasil penelitian ini didukung temuan Wang (2009) $e$-portofolio merupakan alat yang efektif terbantahkan untuk pembelajaran yang aktif, sehingga para dosen perlu mengembangkan keterampilan baru tentang refleksi terintegrasi dalam melaksanakan pembelajaran.

Hasil penelitian Tubaishat (2011) menunjukkan bahwa terdapat dua manfaat utama dari sistem: (a) $e$-portofolio dapat berfungsi sebagai batu penjuru; dan (b) e-portofolio dapat berfungsi sebagai dokumentasi persyaratan akreditasi kelembagaan. Dalam penelitian yang lain Tubaishat (2015) yang menganalisis persepsi dan sikap 217 
mahasiswa College of Technological Innovation menemukan bahwa para mahasiswa memiliki pendapat positif tentang penggunaan $e$-portofolio sebagai alat yang bermanfaat untuk mendukung kesiapan mereka untuk pekerjaan. Mereka menilai bahwa $e$-portofolio meningkatkan kepercayaan diri untuk mencari pekerjaan di bidang informasi dan teknologi karena memungkinkan mereka untuk menampilkan artefak yang menunjukkan kompetensi kepada para supervisor selama pelatihan industri dengan $e$-resume tentang keahlian dan pekerjaan apa yang mampu mereka lakukan setelah menyelesaikan studi.

\section{METODE PENELITIAN}

Tujuan umum penelitian ini adalah untuk menghasilkan dan memvalidasi produk platformeportofolio agar hasil kajian dapat digunakan sebagai rujukan pemilihan platform e-portofolio untuk perkuliahan di Jurusan Kurikulum dan Teknologi Pendidikan Universitas Negeri Jakarta. Untuk mencapai tujuan tersebut, dari 2 tahun yang direncanakan pada tahun pertama penelitian bertujuan memetakan karakteristik tiga buah platform e-portofolio. Pada tahun kedua, diharapkan Pogram Studi Teknologi Pendidikan Fakultas Ilmu Pendidikan Universitas Negeri Jakarta sudah dapat menerapkan $e$-portofolio pada perkuliahannya.

Dari penelitian yang dikembangkan ini diharapkan diperoleh beberapa manfaat, yaitu:

1. Berkembangnya wawasan, bahwasanya diperlukan pembaharuan metode pembelajaran untuk para mahasiswa di era perkembangan teknologi seperti saat ini.

2. Tumbuhnya kesadaran pola berpikir, bahwa dalam menerapkan teknologi dalam proses perkuliahan harus diawali dengan tahapan analisis terlebih dahulu.

3. Manfaat lain adalah, tumbuhnya pola kesinambungan antara kegiatan pembelajaran di perkuliahan dengan di dunia kerja.

4. Merintis pengembangan wawasan penelitian baru dalam bidang teknologi pendidikan yakni menerapkan Design and Development Research (DDR).

a. Membuka wacana bagaimana sebaiknya mengembangkan $e$-portofolio secara ilmiah, berlandaskan teori pembelajaran dan desain pembelajaran.

Penelitian ini dilakukan di Universitas Negeri Jakarta, khususnya Program Studi Teknologi Pendidikan Fakultas Ilmu Pendidikan. Pertimbangan memilih tempat penelitian ini karena program Studi Teknologi Pendidikan adalah Program Studi semenjak tahun 2009 memiliki perhatian besar terhadap metode pembelajaran inovatif. Adapun penelitian tahap 1 ini dilaksanakan dalam kurun waktu 1 tahun, yaitu tahun 2016 .

Obyek penelitian ini adalah software (platform) e-portofolio, sedangkan subyek penelitian ini adalah ahli pembelajaran inovatif dan dosen yang memiliki perhatian terhadap pembelajaran memanfaatkan internet serta para ahli di bidang teknologi informasi.

Ditinjau dari tujuan penelitian dalam menerapan $e$-portofolio untuk perkuliahan di Program Studi Teknologi Pendidikan Universitas Negeri Jakarta, maka penelitian ini dilakukan dengan metode design and development research. Design and development research bertujuan untuk menciptakan pengetahuan yang didasarkan pada data-data yang diperoleh dari proses yang terjadi 
secara sistematis. Rita C. Richey and James D. Klein (2007:1) mendefinisikan design and development research sebagai berikut:

"The systematic study of design, development and evaluation processes with the aim of establishing an emperical basis for the creation of instructional and noninstructional product and tools and new or enhanced models thats govern their development".

Definisi di atas mengungkapkan design \& development research adalah studi sistematis pada desain, pengembangan dan proses evaluasi dengan tujuan membentuk dasar empiris untuk penciptaan produk instruksional dan non-instruksional dan alatalat dan model baru atau yang disempurnakan yang mengatur proses pengembangan.

Dalam design \& development research terdapat dua katagori besar yang dapat diteliti, yaitu penelitian tool use dan model development. Penelitian ini termasuk dalam katagori penelitian tool use serta model development. Salah satu jenis model penelitian dapat digunakan adalah penelitian yang berasal dari designer expertise \& characteristics research. Adapun pengertian dari penelitian yang berorientasi ahli (expert) menurut Blaine R. Worthen and James R. Sanders (1987:98) adalah sebagai berikut:

"The expertise oriented approach depends primarily upon professional expertise to judge an educational institution, program, product, or activity".

Adapun penelitian berorientasi ahli yang digunakan pada penelitian ini termasuk dalam informal review system. Pada informal review system, penelitian dilakukan sesuai dengan waktu yang disepakati oleh para partisipan.

Dalam mencapai tujuan penelitian ini, peneliti mengadaptasi metode penilaian terhadap sebuah software (Scriven, 1991) dan kemudian dikembangkan menjadi 6 (enam) langkah besar sebagai berikut:

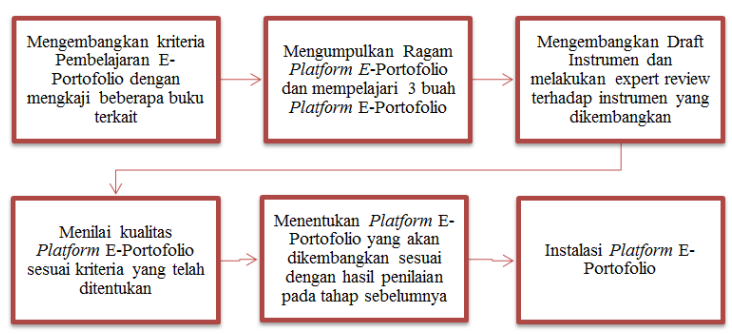

Gambar 1 Alur penelitian

1. Mengembangkan kriteria Pembelajaran $e$ portofolio

Langkah pertama yang dilakukan dalam penelitian pengembangan ini adalah menentukan kriteria sebuah $e$-portofolio dikatakan baik untuk digunakan dalam sebuah pembelajaran. Setelah melalui proses pengkajian dari beberapa sumber teori, maka pada penelitian ini mengadaptasi kriteria ceklis untuk mengevaluasi sistem $e$-portofolio yang dikembangkan oleh Klaus Himpsl dan Peer Baumgartner. Kriteria milik Baumgartner dan Himpsl dipilih dikarenakan pembentukan kriteria untuk mengevaluasi sistem $e$-portofolio menggunakan landasan pedagogik sebagai berikut:

a. Sistem e-portofolio harus dapat memberikan akses kepada peserta didik untuk menggunakan dan mengelola data pribadi peserta didik. Selain itu data peserta didik harus selalu tersedia untuk diakses.

b. Tersedia media untuk komunikasi dan berkolaborasi di antara kelompok peserta didik.

c. Memberikan representasi utuh mengenai peserta didik. 
2. Mempelajari ragam platform e-portofolio

Hingga saat ini terdapat banyak sekali platform e-portofolio, Helen C. Barrett, Ph.D pada tahun 2007 setidaknya menggolong platform e-portofolio menjadi 6 buah, yaitu:

a. Authoring Tools.

These are tools that can be used to author portfolios (offline), but require web server space to publish online. Portfolios created with these tools can also be published on $C D-R$ or DVD-R. No interactivity.

b. Static Web Services.

These are static web services that an individual or institution may use to create and publish a presentation portfolio - little or no interactivity (Web 1.0).

c. Interactive Web Services

These are dynamic web services that an individual or institution may use to create and publish a presentation portfolio and allows interactivity (Web 2.0).

d. Software-Server required

These are systems that an institution would install on their own server to provide space for hosting portfolios. Interactivity but no data management system.

e. Hosted Services

These are systems that an institution adopts (no server required) that host portfolios. Usually supports interactivity but no data management or reporting systems.

f. Assessment Systems - Hosted Services

There are hosted systems that an institution would adopt (no server required) that will allow hosting portfolios, facilitates interactivity, and includes a data management and reporting system for assessment.

3. Mengembangkan draft instrumen penilaian dan melakukan expert review terhadap instrumen yang dikembangkan

Agar instrumen yang digunakan dalam penelitian ini secara valid dapat mengukur secara tepat kriteria-kriteria yang telah ditentukan sebelumnya, maka dilakukan validitas instrumen oleh expert (expert reviews) dengan mempertimbangkan beberapa unsur, meliputi: (1) observasi dari masing-masing elemen yang akan dinilai, (2) kejelasan cara memparafrase butir-butir instrumen, dan (3) efisiensi dari urutan butir-butir instrumen. Expert review dilakukan oleh 3 orang ahli dari sudut pandang yang berbeda-beda. Berdasarkan hasil penilaian, tersebut seluruh draft instrumen dinyatakan valid dan dapat digunakan untuk menilai kualitas e-portofolio yang akan dikembangkan.

4. Menilai kualitas $e$-portofolio tool sesuai kriteria yang telah ditentukan

Setelah melakukan pemetaan mengenai ragam platform e-portofolio, maka tahap ini merupakan tahapan yang sangat penting pada penelitian ini, karena pada tahap ini dilakukan penilaian platform e-portofolio berdasarkan kriteria ceklis yang sudah dikembangkan pada sebelumnya.

5. Menentukan e-portofolio tool yang akan dikembangkan.

Setelah dilakukannya penilaian oleh para ahli, data penilaian tersebut dijadikan acuan oleh peneliti berserta tim pengembang untuk memilih platform e-portofolio yang akan dikembangkan. Jika sebelumnya penilaian diklasifikasikan per narasumber, maka pada tahap ini data diklasifikasi per aspek.

Jika dilihat dari tahap 3, maka pengembang memiliki tingkat kesulitan dalam memilih tool. Hal ini disebabkan, Narasumber 1 dan 4 menilai mahara yang memiliki kriteria terbaik, sedangkan Narasumber 2 dan 3 menilai Elgg yang memiliki kriteria terbaik. Sehingga diputuskan bahwa mahara adalah platform e- 
portofolio yang akan ditetapkan sebagai platform yang akan dikembangkan.

6. Instalasi $e$-portofolio tool

Tahap terakhir dalam penelitian ini adalah menginstal platform mahara sebagai tool $e$-portofolio pada website resmi www.eportofolio.ac.id. Dengan berakhirnya tahapan ini, maka tujuan penelitian periode pertama ini diharapkan sudah tercapai, yaitu memetakan karakteristik dari empat buah platform e-portofolio dan menetapkan mahara sebagai platform e-portofolio yang akan dikembangkan.

\section{HASIL DAN PEMBAHASAN}

a. Hasil Penelitian

Penelitian ini bertujuan memetakan 3 (tiga) buah karakteristik platform untuk dimanfaatkan sebagai e-portofolio. Adapun hasil dari pemetaan tersebut adalah:

Tabel 2. Hasil Penelitian

\begin{tabular}{|c|l|l|l|l|}
\hline \multicolumn{2}{|c|}{ Aspek } & elg9, & fnooded & \&mahara \\
\hline 1 & $\begin{array}{l}\text { Aspek } \\
\text { Mengumpulkan, } \\
\text { Mengorganisir, } \\
\text { Memilih }\end{array}$ & 4,13 & 3,22 & 3,97 \\
\hline 2 & $\begin{array}{l}\text { Aspek } \\
\text { Merefleksikan, } \\
\text { Menguji, } \\
\text { Verifikasi dan } \\
\text { Merencanakan }\end{array}$ & 4.04 & 3,14 & 4,35 \\
\hline 3 & $\begin{array}{l}\text { Aspek } \\
\text { Penyajian dan } \\
\text { Penerbitan }\end{array}$ & 3,85 & 3,25 & 4,1 \\
\hline 4 & $\begin{array}{l}\text { Aspek } \\
\text { Pengadministra- } \\
\text { sian, } \\
\text { pelaksanaan, } \\
\text { Pengadministras } \\
\text { ian }\end{array}$ & 3,75 & 4,3 & 4,5 \\
\hline 5 & $\begin{array}{l}\text { Aspek } \\
\text { Penggunaan }\end{array}$ & 4,29 & 3,5 & 4,27 \\
\hline Rata-rata & 4,005 & 3,482 & 4,238 \\
\hline
\end{tabular}

Selain dari data statistik, mahara dipilih untuk selanjutnya dikembangkan dengan pertimbangan:

1. Sebagai bagian dari sistem $e$-learning, platform $e$-portofolio mahara dan moodle jauh lebih siap dalam merefleksikan, menguji, verifikasi dan merencanakan dibandingkan dengan elgg. dalam mengintegrasikan tools yang dimilikinya dengan e-learning.

2. Secara penyajian dan penerbitan mahara hampir sempurna sebagai platform e-portofolio, sedangkan elgg penyajiannya terlalu sederhana.

3. Platform moodle secara penerbitan lebih kompleks dan terlihat rumit. Sehingga perlu pengaturan yang lebih cermat dibandingkan elgg dan mahara

4. Dalam hal penggunaan interface, kualitas navigasi, kualitas bantuan pengoperasian, kemudahan mengganti konten serta kemudahan mengadaptasi sesuai kebutuhan topik portofolio serta kemudahan menyimpan file (dari komputer ke platform) mahara lebih unggul dibanding moodle dan ellg.

5. Hanya saja mahara memiliki kelemahan dalam mendownload file yang tersimpan yaitu ketika membuka halaman portofolio, kita secara langsung mendownload file yang diakses, meskipun belum ada intruksi untuk mendownload file.

Berdasarkan pertimbangan tersebut, maka mahara dipilih untuk dikembangkan sebagai tools $e$ portofolio. Mahara yang dikembangkan ini dilakukan pada subdomain www.eportofolio.ac.id. Sasaran pengguna dari produk ini adalah seluruh dosen dan mahasiswa Universitas Negeri Jakarta secara umum, dan Program Studi Teknologi 
Pendidikan secara khusus.

b. Karakteristik e-portofolio yang dikembangkan.

1) Spesifikasi

Spesifikasi pada mahara sebagai produk hasil pengembangan ini adalah:

a. Mahara dikembangkan dengan server kapasitas hosting $10 \mathrm{~GB}$, dengan kapasitas traffic data transfer unlimited per bulan.

b. Menggunakan platform mahara ver. 15.10.0 (http://mahara.org).

2) Kelebihan

Beberapa kelebihan mahara sebagai produk hasil pengembangan ini adalah:

a. Mahara dipilih dengan sebelumnya dikaji secara konsep pembelajaran yang menyeluruh disegala aspek.

b. Mahara memiliki aksesbilitas tinggi, ini buktikan dengan akses yang dapat dilakukan melalui mobile internet.

c. Mahara memiliki fleksibilitas tinggi bagi pengembang konten. fleksibilitas ini terlihat dari bebasnya content designer dalam memilih aplikasi apa saja yang akan digunakan dalam kelas virtualnya.

d. Memiliki subdomain yang bergengsi dan bersifat general, yaitu www.eportofolio.ac.id. Dengan sifatnya yang general, maka domain ini dapat dimanfaatkan secara luas dalam bidang pendidikan.

3) Keterbatasan pengembangan.

Keterbatasan pada pengembangan ini adalah sulitnya memperoleh ahli yang mampu dan memiliki waktu dalam menilai 3 buah platform. Selain dari itu, ahli dalam penelitian ini berjumlah 4 orang dan memberikan penilaian dalam posisi imbang. Sehingga, ada keraguan oleh pengembang untuk memilih platform yang akan digunakan.

\section{KESIMPULAN}

Sesuai dengan perkembangan teknologi maka format portofolio saat ini berkembang menjadi elektronik portofolio (e-portofolio). Potensi dari $e$ portofolio sama besar dengan potensi portofolio konvensional hanya melalui $e$-portofolio sifat dinamis teknologi akan menyertai format ini. Saat ini sudah banyak software yang dapat digunakan untuk mengembangkan $e$-portofolio, baik software yang berdiri sendiri (stand alone) ataupun software yang dirangkaikan dalam sebuah Learning Content Management System (LCMS).

Berdasarkan hasil penelitian ini, maka peneliti menyimpulkan platform mahara adalah platform yang sesuai untuk dimanfaatkan dalam proses pembelajaran. Hal ini didukung penilaian para ahli yang diperoleh.

\section{DAFTAR RUJUKAN}

Amy Solomo,et.al., 2012, 100\% Job Search Success, Second Edition, (Boston, Cengage Learning.

Ahmet Erdost Yastibas and Gü lsah Cinar Yastibas ,The use of e-portfolio-based assessment to develop students' self-regulated learning in English language teaching, Procedia Social and Behavioral Sciences 176 ( 2015 ) $3-13$

Brown, George A., Bull, Joanna dan Pendlebury, Malcolm, Assessing Student Learning in Higher Education, New York: Routledge, 1997.

Buzzetto-More, Nicole, Assessing the Efficacy and Effectiveness of an E-Portfolio Used for Summative Assessment, Interdisciplinary Journal of E-Learning and Learning Objects Volume 6, 2010

Gabel, D.L. (1993). Handbook of Research on Science Teaching and Learning. New York: Maccmillan Company. 
Helen C. Barrett, Ph.D, Categories of ePortfolio Tools,http://electronicportfolios.org/categori es.html, diakses 9 Juli 2016.

Information Research Management Association, Cyber Behavior: Concepts, Methodologies, Tools, and Applications, Hershey: IGI Global, 2014.

Inoue Yukiko (ed), Cases on Online and Blended Learning Technologies in Higher Education :Concepts and Practices, New York: IGI Global, 2010.

Inoue Yukiko (ed), Cases on Online and Blended Learning Technologies in Higher Education :Concepts and Practices, New York: IGI Global, 2010.

Intelligent Interaction, Berlin: Springer, 2012.http://en.wikipedia.org/wiki/Digital_na tive

Kelly,Martina dalam Lyon, Nona (Ed), Handbook of Reflection and Reflective Inquiry: Mapping a Way of Knowing for Professional Reflective Inquiry, New York: Springer, 2010.

Keputusan Menteri Pendidikan Nasional Nomor 107/U/2001 tentang Pendidikan Jarak Jauh

Kumano, Y. 2001. Authentic Assessment and Portfolio Assessment-Its Theory and Practice. Japan: Shizuoka University.

Lorraine Stefani, Robin Mason, and Chris Pegler (2007), The Educational Potential of Eportfolios: Supporting Personal Development and Reflective Learning New York: Routledge

Mardina, Riana. Potensi Digital Natives DalamRepresentasiLiterasiInformasi

Multimedia Informasi Multimedia Berbasis Web Di PerguruanTinggi. JurnalPustakawan Indonesia Volume 11 No. 1

McNeill, M. \& Cram, A. (2011). Evaluating Eportfolios for university learning: Challenges and Opportunities. In G. Williams, P. Statham, N. Brown \& B. Cleland (Eds.), Changing Demands, Changing Directions. Proceedings ascilite Hobart 2011. (pp.862-873)

Ministry of Education New Zealand, (2011). Digital Portfolios, Guidelines for beginners, Wellington, New Zealand.

Nicole Buzzetto-More (Ed), The E-portfolio
Paradigm: Informing, Educating, Assessing, and Managing with E-Portfolios, California: informing Science Press, 2010.

Peraturan Menteri Pendidikan Dan Kebudayaan Republik indonesia Nomor 49 tahun 2014 tentang Standar Nasional Pendidikan Tinggi.

R. Worthen, Blaine (1987). Educational Evaluation. New york \& London, Longman.

Rassin et al. dalam Fiona Timmins, Making Sense of Portfolios: a Guide for Nursing Students, (New York: McGraw Hill, 2008), h. 22

Richey, Rita C. and Klein, James D, (2007). Design and Development Research, New Jersey.

Shouhong Wang, E-Portfolios for Integrated Reflection, Issues in Informing Science and Information Technology Volume 6, 2009.

Stefani, Lorraine, Mason, Robin, and Pegler, Chris, The Educational Potential of E-portfolios: Supporting Personal Development and Reflective Learning, New York: Routledge , 2007.

Surapranata, Sumarna dan Muhammad Hatta, (2006). Penilaian Portofolio: Implementasi Kurikulum 2004. Bandung.

The Online Journal Of New Horizons In Education October 2011, Volume 1, Issue 4, Eportofolio Applications In Education.

Tubaishat, A. (2015). Can e-portfolio improve students' readiness to find an IT Career? Issues in Informing Science and Information Technology, 12, 198-202

Tubaishat, Abdallah, ePortfolio: Expanding the Information Technology Vision to Serve as a Capstone in an Outcome-Based University, International Journal of Information and Communication Technology Research, Volume 1 No. 4, August 2011.

Yan, Sufeng, Song, Runjuan, and Sun, Liming dalam Luo, Jia (Ed), Affective Computing and

Yuanchun, Wenyin Liu dan Li, Shi Qing (Eds.), Advances in Web-Based Learning- ICWL Third International Conference Beijing, China, August 8-11, 2004 (Proceedings).

Zulkifli MatondangModul 3, Pengembangan Asesmen Alternatif 